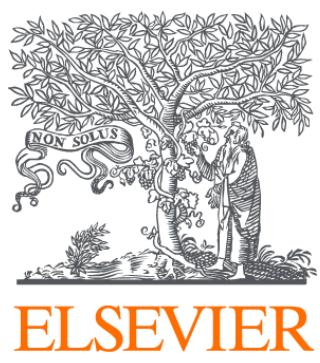

Since January 2020 Elsevier has created a COVID-19 resource centre with free information in English and Mandarin on the novel coronavirus COVID-

19. The COVID-19 resource centre is hosted on Elsevier Connect, the company's public news and information website.

Elsevier hereby grants permission to make all its COVID-19-related research that is available on the COVID-19 resource centre - including this research content - immediately available in PubMed Central and other publicly funded repositories, such as the WHO COVID database with rights for unrestricted research re-use and analyses in any form or by any means with acknowledgement of the original source. These permissions are granted for free by Elsevier for as long as the COVID-19 resource centre remains active. 


\section{Evaluating risk to people with epilepsy during the COVID-19 pandemic: Preliminary findings from the COV-E study}

\section{Jennifer Thorpe a,b, Samantha Ashby ${ }^{b}$, Asma Hallab ${ }^{c}$, Ding Ding ${ }^{\mathrm{d}}$, Maria Andraus ${ }^{\mathrm{e}}$, Patricia Dugan ${ }^{\mathrm{f}}$, Piero Perucca $^{\mathrm{g}}$, Daniel Costello ${ }^{\mathrm{h}}$, Jacqueline A. French ${ }^{\mathrm{f}}$, Terence J. O’Brien ${ }^{\mathrm{g}}$, Chantal Depondt ${ }^{\mathrm{i}}$, Danielle M. Andrade ${ }^{j}$, Robin Sengupta ${ }^{k}$, Norman Delanty ${ }^{1}$, Nathalie Jette ${ }^{\mathrm{m}}$, Charles R. Newton ${ }^{\mathrm{a}, \mathrm{n}}$, Martin J. Brodie ${ }^{\circ}$, Orrin Devinsky ${ }^{f}$, J. Helen Cross ${ }^{\mathrm{p}, \mathrm{q}}$, Josemir W. Sander ${ }^{\mathrm{r}, \mathrm{s}}$, Jane Hanna ${ }^{\mathrm{b}}$, Arjune Sen ${ }^{\mathrm{a}, *}$, on behalf of the COVID-19 and Epilepsy (COV-E) Study Group}

\footnotetext{
a Oxford Epilepsy Research Group, NIHR Biomedical Research Centre, Nuffield Department of Clinical Neurosciences, John Radcliffe Hospital, Oxford OX3 9DU, UK b SUDEP Action, 18 Newbury Street, Wantage, Oxfordshire OX12 8DA. UK

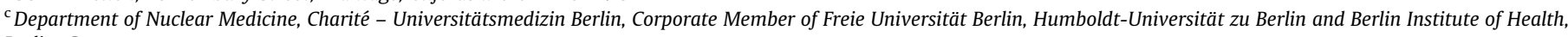
Berlin, Germany

${ }^{\mathrm{d}}$ Institute of Neurology, Fudan University Huashan Hospital, Shanghai, China

e Department of Internal Medicine, Neurology Service, Epilepsy Program, Clementino Fraga Filho University Hospital, Federal University of Rio de Janeiro, Rio de Janeiro, Brazil ${ }^{\mathrm{f}}$ Department of Neurology, NYU Grossman School of Medicine, USA

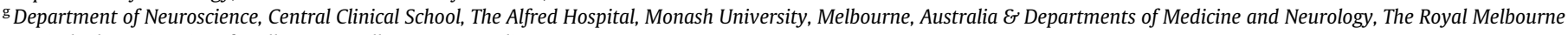
Hospital, The University of Melbourne, Melbourne, Australia

${ }^{\mathrm{h}}$ Epilepsy Service, Cork University Hospital E' College of Medicine and Health, University College Cork, Ireland

i Department of Neurology, Hôpital Erasme - Université Libre de Bruxelles, Brussels, Belgium

${ }^{\mathrm{j}}$ Adult Epilepsy Genetics Program, Toronto Western Hospital, University of Toronto, Toronto, Canada

${ }^{\mathrm{k}}$ The Institute of Neurosciences, Kolkata, India

${ }^{1}$ Beaumont Hospital, and School of Pharmacy and Biomolecular Sciences, FutureNeuro Research Centre, Royal College of Surgeons in Ireland, Dublin, Ireland

${ }^{\mathrm{m}}$ Department of Neurology, Icahn School of Medicine at Mount Sinai, New York, USA

${ }^{\mathrm{n}}$ University Department of Psychiatry, University of Oxford, UK

${ }^{\circ}$ Epilepsy Unit, West Glasgow Ambulatory Care Hospital-Yorkhill, Glasgow, UK

${ }^{\mathrm{P}}$ UCL NIHR BRC Great Ormond Street Institute of Child Health, London, UK

${ }^{\mathrm{q}}$ Young Epilepsy, St Pier's Lane, Dormansland, Lingfield RH7 6P, UK

${ }^{\mathrm{r}}$ UCL Queen Square Institute of Neurology, Queen Square, London WC1N 3BG \& Chalfont Centre for Epilepsy, Chalfont St Peter SL9 0RJ, UK

${ }^{\mathrm{s}}$ Stichting Epilepsie Instellingen Nederland (SEIN), Heemstede, Netherlands
}

\section{A R T I C L E I N F O}

\section{Article history:}

Received 28 October 2020

Revised 22 November 2020

Accepted 22 November 2020

Available online $\mathrm{xxxx}$

\section{Keywords:}

Coronavirus

Chronic illness

Mental health

Seizures

SUDEP

\begin{abstract}
A B S T R A C T
The COVID-19 pandemic has caused global anguish unparalleled in recent times. As cases rise, increased pressure on health services, combined with severe disruption to people's everyday lives, can adversely affect individuals living with chronic illnesses, including people with epilepsy. Stressors related to disruption to healthcare, finances, mental well-being, relationships, schooling, physical activity, and increased isolation could increase seizures and impair epilepsy self-management.

We aim to understand the impact that COVID-19 has had on the health and well-being of people with epilepsy focusing on exposure to increased risk of seizures, associated comorbidity, and mortality. We designed two online surveys with one addressing people with epilepsy directly and the second for caregivers to report on behalf of a person with epilepsy.

The survey is ongoing and has yielded 463 UK-based responses by the end of September 2020. Forty percent of respondents reported health changes during the pandemic $(n=185)$. Respondents cited a change in seizures $(19 \%, n=88)$, mental health difficulties $(34 \%, n=161)$, and sleep disruption $(26 \%$, $n=121$ ) as the main reasons. Thirteen percent found it difficult to take medication on time. A third had difficulty accessing medical services $(n=154)$, with $8 \%$ having had an appointment canceled $(n=39)$. Only a small proportion reported having had discussions about epilepsy-related risks, such as safety precautions $(16 \%, n=74)$; mental health $(29 \%, n=134)$; sleep $(30 \%, n=140)$; and Sudden Unexpected Death in Epilepsy (SUDEP; 15\%, $n=69$ ) in the previous 12 months.
\end{abstract}

\footnotetext{
* Corresponding author at: Department of Neurology, 3rd Floor, West Wing, John Radcliffe Hospital, Oxford OX3 9DU, UK.

E-mail address: arjune.sen@ndcn.ox.ac.uk (A. Sen).
} 


\begin{abstract}
These findings suggest that people with epilepsy are currently experiencing health changes, coupled with inadequate access to services. Also, there seems to be a history of poor risk communication in the months preceding the pandemic. As the UK witnesses a second COVID-19 wave, those involved in healthcare delivery must ensure optimal care is provided for people with chronic conditions, such as epilepsy, to ensure that avoidable morbidity and mortality is prevented during the pandemic, and beyond.
\end{abstract}

(c) 2020 Elsevier Inc. All rights reserved.

\section{Introduction}

The COVID-19 pandemic has created particular challenges for people with chronic illness, who may have greater susceptibility to adverse consequences beyond direct risks from infection [1-3]. People with epilepsy are generally not considered to be more likely to contract COVID-19, or necessarily develop a more significant illness in case of infection [4,5]. The indirect consequences of the pandemic could, however, impair their health and well-being in numerous ways [2]. Stressors, including economic challenges, anxiety, isolation, decreased physical activity, as well as interruptions to schooling, work, and family life, may increase seizures [6,7]. Disruption to self-management practices, such as adherence to anti-seizure medications (ASMs), and a lack of access to healthcare may also play a role [8-10]. Together, these factors could increase seizures, worsen associated psychiatric comorbidities such as anxiety and depression, and contribute to an increased risk of premature mortality [11].

Medical services have reconfigured rapidly during the pandemic. In the United Kingdom (UK), many epilepsy nurses and neurologists with an interest in epilepsy were redeployed into general medical services, resulting in the temporary closure of epilepsy clinics [12]. Video-EEG monitoring and other elective admissions were suspended. Access to neuropsychology was significantly limited, and epilepsy surgery was postponed $[13,14]$.

The pandemic has also sharply accentuated inequality on multiple levels $[15,16]$. For example, health service disruptions are likely to have a greater impact on vulnerable populations, including Black, Asian and Minority Ethnic (BAME) groups, the elderly, and people from lower socioeconomic strata [17-19]. All of these factors are predicted to adversely affect those with epilepsy, particularly those at high risk [17-21].

To examine this, the COVID-19 and Epilepsy (COV-E) Study Group, led by SUDEP Action \& University of Oxford, launched online surveys to assess the experiences of people with epilepsy through the first wave of the pandemic. We aimed to understand the impact of COVID-19 on people's health and well-being. Specifically, we evaluated whether people's exposure to risk had changed, including an increased risk of seizures, worsening morbidity, and their corresponding risk of premature mortality. While the surveys achieved a global reach in multiple languages, here we present the UK data. These data are derived from people with epilepsy and their caregivers, submitted during the first four months of the COVID-19 pandemic when the high rate of new COVID-19 infections had a considerable impact on epilepsy services [3,24]. We explore various themes associated with COVID-19 and epilepsy, including respondents' demographics, health status, and their interactions with health services. We also assessed knowledge and exposure to risk, including factors associated with premature mortality in people with epilepsy [20-23].

\section{Methods}

\subsection{Study design}

In April 2020, we designed separate surveys for people with epilepsy and primary caregivers [https://sudep.org/epilepsy-risks- and-covid-19-survey-people-epilepsy; Supplementary material] hosted on Jisc online survey software (https://www.onlinesurveys.ac.uk/). Pilot testing was performed on volunteer people with epilepsy before the online launch. Initial surveys were in English and these have since been translated into 11 languages. The surveys focus on quantitative data collection while also presenting participants with the opportunity to provide qualitative data through free-text answers. The study was approved by the University of Oxford Ethics Committee (Reference: R69353/RE001).

Inclusion criteria stipulated that people completing the survey had to be over the age of 18 years and be a person with epilepsy or someone who cares for a child or adult with epilepsy. Participants were provided with study information and completed an online consent form. All data were collected online, and data entry was anonymous. Healthcare workers were also surveyed, data from which will be presented in future publications.

\subsection{Measurements}

\subsubsection{Demographics}

People with epilepsy provided background information including their age, gender, ethnic background, and postcode information $[25,26]$.

\subsubsection{Epilepsy type/health background}

Respondents were asked about epilepsy type, seizure type(s), and frequency; nocturnal events; medications; primary epilepsy care provider; the number of specialist visits in the past year; unplanned/emergency hospital admissions due to epilepsy; associated injuries; and comorbidities. People were asked if they had contracted COVID-19 or had to self-isolate owing to possible exposure.

\subsubsection{Risk factors for epilepsy morbidity and mortality}

We enquired about changes in behavior, habits, and circumstances during the pandemic, potentially associated with increased risk. Specific questions were included that related to mental health status, alcohol and drug consumption, sleeping patterns, and changes to seizures $[21-23,27]$. We asked about individual living circumstances and whether respondents lived alone or with someone who could provide first aid [28].

We explored the discussion of risk between the participant and their clinician in the previous 12 months. We asked, where relevant, whether the following had been discussed: ASM side effects, rescue medication, alcohol, contraception, driving, life changes, employment, mental health, pregnancy, recreational drugs, safety aids, first aid, sleep, stigma, and Sudden Unexpected Death in Epilepsy (SUDEP) [21-23,27].

\subsubsection{Access to healthcare}

We investigated if there had been an impact on healthcare access (e.g. experience in obtaining prescriptions, changes to arranged appointments, communication with clinicians), and user satisfaction. Participants were encouraged to provide free-text answers to contextualize their responses. 


\subsubsection{Caregiver survey}

The caregiver survey mirrored that of the person with epilepsy survey to ascertain the impact of COVID-19 on the individual with epilepsy, through a caregiver's perspective. Caregivers were asked about their relationship to the person with epilepsy (e.g. parent, remunerated caregivers). Questions allowed caregivers to disclose gaps in their knowledge of the person's background, health status, or treatment plan. In such instances, respondents could select "unsure" or "don't know" options and elaborate where relevant.

\subsection{Dissemination}

Survey dissemination was led by SUDEP Action and was also shared on social media and promoted by multiple epilepsy support organizations, including, but not limited to, the BAND Foundation, Citizens United for Research in Epilepsy (CURE), Epilepsy Action, Epilepsy Foundation America, Epilepsy Research UK, Epilepsy Society, Epilepsy Sparks, the International Bureau for Epilepsy (IBE) and the International League Against Epilepsy (ILAE) (see acknowledgments).

\subsection{Data analysis}

Data collection is ongoing. We collated data in the UK from April to September 2020 and categorized these into: i) demographics; ii) reported health outcomes; iii) awareness of risk; and iv) access to epilepsy care.

Each survey was first analyzed in isolation, utilizing descriptive statistics and cross-tabulation of data using tools provided by Jisc. Data were then exported into Microsoft Excel, enabling crosscomparison of individual and caregiver surveys. We compared qualitative and quantitative data $[29,30]$ to clarify responses, particularly for ethnicity, comorbidities, medication, and hospital admissions. Postcode data were processed using mapping tools provided by Datawrapper to produce choropleth maps of the geographic distribution of responders.

We further analyzed data from groups at potentially heightened vulnerability, including those who identify as members of BAME communities [17-19], people who are pregnant, people over the age of 60 , and those who experience other comorbid conditions that make them directly vulnerable to COVID-19 [2,15]. Data analyses used descriptive statistics, case reports, and qualitative coding of free-text data $[29,31]$. Statistically significant conclusions were not drawn where the sample size was $n \leq 50$.

\section{Results}

We received 463 responses, 68\% from people with epilepsy $(n=316)$, and $32 \%$ from caregivers on behalf of a person with epilepsy $(n=147)$.

\subsection{Population demographics}

\subsubsection{Geographical distribution}

Data were collected from 106 of the 122 UK postcode areas with greater representation from the South East, the Midlands, and the East of England. Urban centers included Birmingham $(n=15)$, Liverpool $(n=11)$ and London $(n=23)$ (Fig. 1). Ninety percent of respondents live in England and Wales $(n=416), 6 \%$ in Scotland $(n=30)$, and $3 \%$ in Northern Ireland $(n=15)$. Two respondents did not provide valid postcodes.

\subsubsection{Gender}

The people with epilepsy survey yielded a greater response rate from females $(78 \%, n=246)$. Twenty percent identified as male
( $n=64)$ and $<1 \%$ as nonbinary $(n=2)$. Two percent did not disclose their gender $(n=4)$.

In the caregiver survey, $49 \%$ identified as female $(n=72)$ and $50 \%$ as male $(n=74)$. One respondent did not disclose their gender.

\subsubsection{Age}

People under 18 were highly represented in the caregiver survey, accounting for $61 \%$ of responses (Table 1 ). Across both surveys, response rates were higher in younger age groups and decreased with age (Fig. 2).

\subsubsection{Ethnicity}

In total, $2 \%$ of respondents identified as belonging to an ethnic minority group $(n=8)$. An additional $5 \%$ of respondents were unsure or did not disclose the relevant information $(n=24)$. Seventeen responses were omitted from analysis as they identified themselves as belonging to a group that is not regarded as a minority ethnic identity in the UK $[26,32,33]$.

\subsubsection{Comorbidities}

Respondents reported a range of other health conditions, which could make them directly or indirectly vulnerable during the pandemic [2,34-37]. A small number of people reported conditions associated with COVID-19 complications, including diabetes $(2 \%, n=7)$, heart problems $(5 \%, n=23)$, hypertension $(5 \%$, $n=23)$ or a respiratory condition $(10 \%, n=44)$. Other prevalent health conditions included intellectual disabilities $(13 \%, n=62)$, memory difficulties $(31 \%, n=143)$, and mental health difficulties $(27 \%, n=123)$.

\subsection{Exposure to risk during the COVID-19 pandemic}

\subsubsection{Health and well-being}

Forty percent of respondents reported a change in health or in the health of the person they care for $(n=185)$. Overall, $19 \%$ reported changes in frequency, type, and length of seizures $(n=88)$, although it was not possible to always determine if this was a positive or a negative change. Qualitative data analysis did, though, demonstrate a worsening in seizure profile for some respondents. $26 \%$ recorded disrupted sleep patterns $(n=121)$; and $34 \%$ increased mental strain, stress, worry, anxiety, or depression $(n=161)$. In responses from people over the age of 18 years, $4 \%$ reported increased alcohol consumption $(n=14)$, while $2 \%$ reported increased recreational drug consumption $(n=6)$.

Of those who take ASMs (total $n=454$ ), $13 \%$ reported greater difficulties in taking them on time $(n=57)$. Changes to routine ( $8 \%, n=38)$, difficulty in acquiring prescriptions $(3 \%, n=15)$, and stress $(7 \%, n=32)$ were cited as the predominant causes for impaired adherence (Fig. 3). An analysis of qualitative data provides additional insights into why these changes may have occurred. Six caregivers reported that changes to schooling and lifestyle contributed to declining mental and physical health in the person for whom they care. Notably, two caregivers reported improved health outcomes as the individual with epilepsy had fewer infections and benefited from spending more time at home. Twenty-five pieces of anecdotal data from the individual survey identified factors contributing to their declining health (Table 2). Four respondents in the people with epilepsy survey reported improved mental health owing to a reduced need to travel or commute and an overall healthier and more relaxed lifestyle.

\subsubsection{Access to healthcare}

3.2.2.1. Prescriptions. Of people taking ASMs (total $n=454$ ), $4 \%$ reported delays in prescription deliveries $(n=16) ; 3 \%$ reported problems in ordering prescriptions $(n=14)$; and $3 \%$ difficulties in collecting their prescription $(n=14)$. Qualitative data highlight 


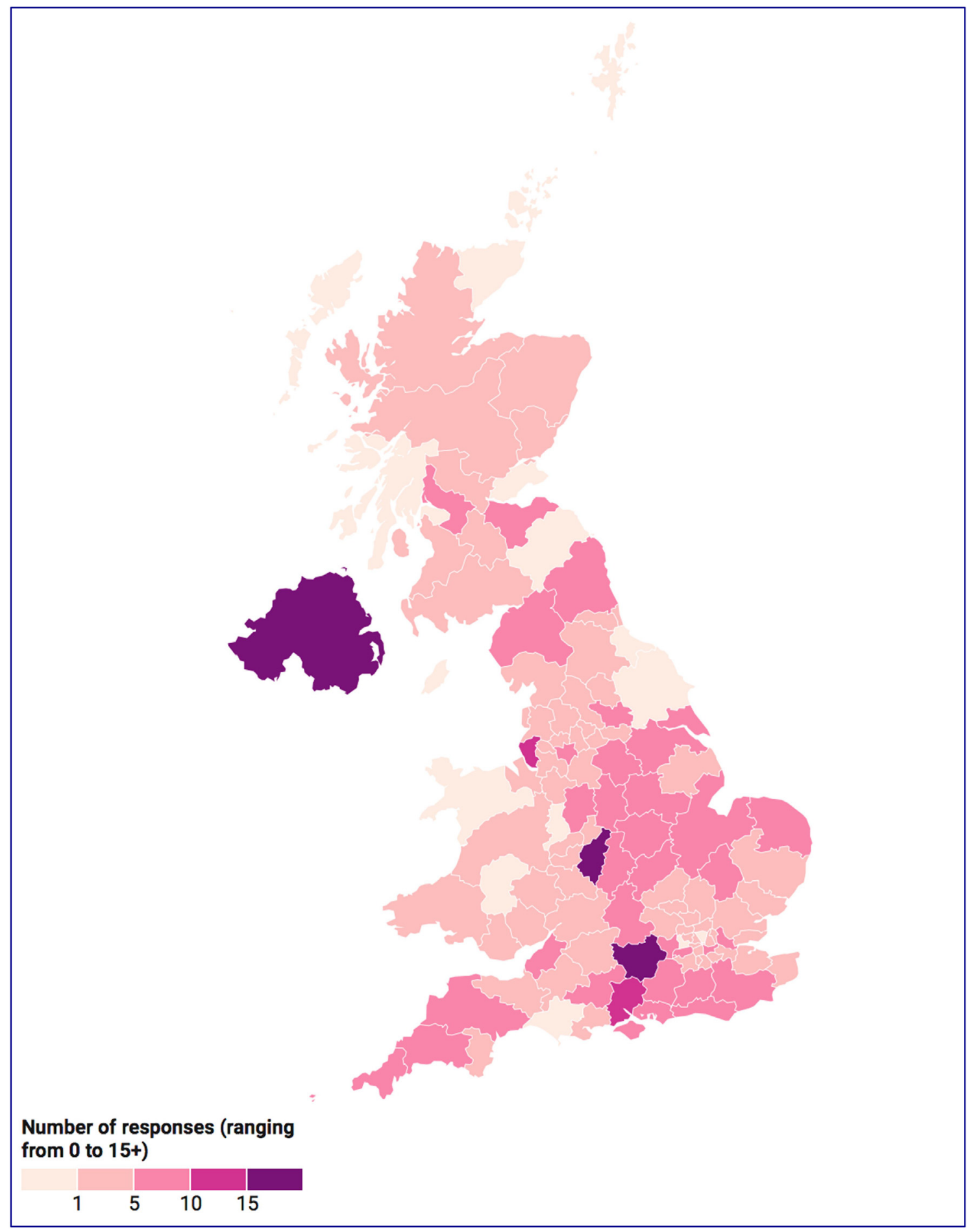

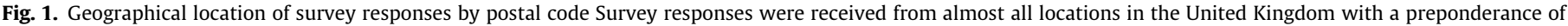
responses from the south of England and the Midlands. Created using datawrapper.de.

additional problems, including difficulty acquiring a repeat prescription and contacting primary healthcare physicians (General Practitioner, GP) or pharmacists. Five respondents, whose treatment plan had changed before or during the lockdown, reported that their new treatment plan had not been processed or adequately supported by their healthcare providers.

3.2.2.2. First aid. A quarter of people with epilepsy were living alone during lockdown $(n=112)$. In the sample of people who live alone, only $23 \%(n=26 / 112)$ had discussed safety aids (seizure alarms, diaries) with an epilepsy specialist in the previous 12 months ( $n=26 / 112)$, and $15 \%$ had discussed safety precautions and first aid ( $n=17 / 112)$.

Additionally, of the 346 participants who reported living with another household member, $15 \%$ did not live with anyone who could provide first aid $(n=53 / 346)$.

3.2.2.3. Emergency care. Thirty-eight percent of respondents across both surveys reported acquiring injuries or needing emergency care due to epilepsy or related injuries during the previous 
Table 1

Age distribution of survey participants. The under-18 years of age group had the largest representation in carer survey, surpassing all other age categories. Participants aged 18-29 were the most represented in the people with epilepsy survey and overall.

\begin{tabular}{llll}
\hline Age range & People with epilepsy & Caregivers & Total \\
\hline Under 18 & N/A & 89 & 89 \\
$18-29$ & 85 & 33 & 118 \\
$30-39$ & 80 & 9 & 89 \\
$40-49$ & 61 & 10 & 71 \\
$50-59$ & 56 & 3 & 59 \\
60 and over & 32 & 2 & 34 \\
Unspecified & 2 & 0 & 2
\end{tabular}

12 months (total $n=176$ ). Qualitative data show at least 11 people have had more than one emergency admission in the past 12 months, with an additional eight respondents requiring hospitalization of a day or more. Forty-one percent of the 176 people who have been injured or required emergency care in the past 12 months lived alone during the lockdown $(n=46 / 176)$.

3.2.2.4. Epilepsy services. A third of respondents reported difficulty accessing epilepsy services $(n=154)$, describing particular difficulty in reaching neurology, GP, and pharmacy services (Fig. 4). Qualitative data indicate that these difficulties stem from the cancellation or postponement of services, or changes to services. For example, people reported a change in the healthcare facility or clinician, or services being provided through virtual technologies.

Quantitative data from both surveys revealed that $48 \%$ of all respondents had a planned medical appointment changed $(n=221)$ and $8 \%$ had appointments canceled $(n=39)$. Twentytwo percent of respondents had not had any communication about prescheduled appointments $(n=100)$.

In analysis of the results from participants who had seen changes to their appointments (total $n=221$ ), $25 \%$ were to take place later in the year ( $n=56 / 221) ; 48 \%$ by telephone as originally scheduled ( $n=107 / 221)$; and $17 \%$ by telephone at ater time $(n=38 / 221)$. Only $9 \%$ of participants were offered video consultations $(n=19 / 221)$. Six percent of video consultations were to take place at the originally scheduled time $(n=13 / 221)$, while $3 \%$ had video appointments moved to a different time $(n=6 / 221)$.

In total, across both surveys, $37 \%$ of individuals reported being satisfied with the current status of their next consultation ( $n=173 / 463)$. Thirty-four percent reported being unsatisfied or unsure $(n=147 / 463)$ and $29 \%$ did not comment ( $n=143 / 463)$. Qualitative data indicate that several respondents consider inperson appointments to be preferable, particularly for those with additional disabilities, including autism and hearing loss, who face additional challenges in adapting to health service delivery through telecommunication.

\subsubsection{Risk awareness}

Analysis of both surveys showed that few respondents reported communication on enduring risks, such as safety precautions (for example, carers being aware of first aid, not swimming in open water; $16 \%, n=74)$; mental health $(29 \%, n=134)$; sleep $(30 \%$, $n=140$ ); and SUDEP (15\%, $n=69$ ). $20 \%$ of respondents had not engaged in patient-clinician communication on any listed risk factors in the past 12 months ( $n=92$; Fig. 5 ). Of the 92 respondents who reported complete nonengagement on risk, 39\% also reported seeing a healthcare professional less than once per year ( $n=44 / 92)$. Risk awareness data varied between individual and caregivers surveys, likely owing to the high proportion of children in the caregiver survey, where risk factors and issues may differ from adults. Some risk factors included in the people with epilepsy survey may not be relevant for all individuals [27].

\subsection{Special groups}

\subsubsection{Black, Asian and Minority Ethnic (BAME)}

Four out of eight BAME participants reported changes to their health, citing changes in seizure activity $(n=1)$, sleep disruption $(n=2)$, and mental strain $(n=2)$ as reasons for this (Table 3$)$. One respondent reported feeling healthier and more relaxed. Four respondents reported difficulty in accessing health services, including neurology $(n=3)$, general hospital services $(n=2)$, general practice $(n=1)$ and out-of-hours services $(n=1)$, pharmacy services $(n=1)$, NHS helpline services $(n=1)$, learning disability services $(n=1)$, occupational therapy $(n=1)$, physical therapy $(n=1)$ and speech therapy $(n=1)$. Multiple responses to these questions were permitted to cover all difficulties respondents had experienced.

Seven respondents demonstrated regular engagement with epilepsy specialists, with just one participant seeing an epilepsy specialist less than annually. No respondents had discussed alcohol consumption, drug use, or stigma. Two respondents reported that there had been no discussion on risk factors in the previous 12 months.

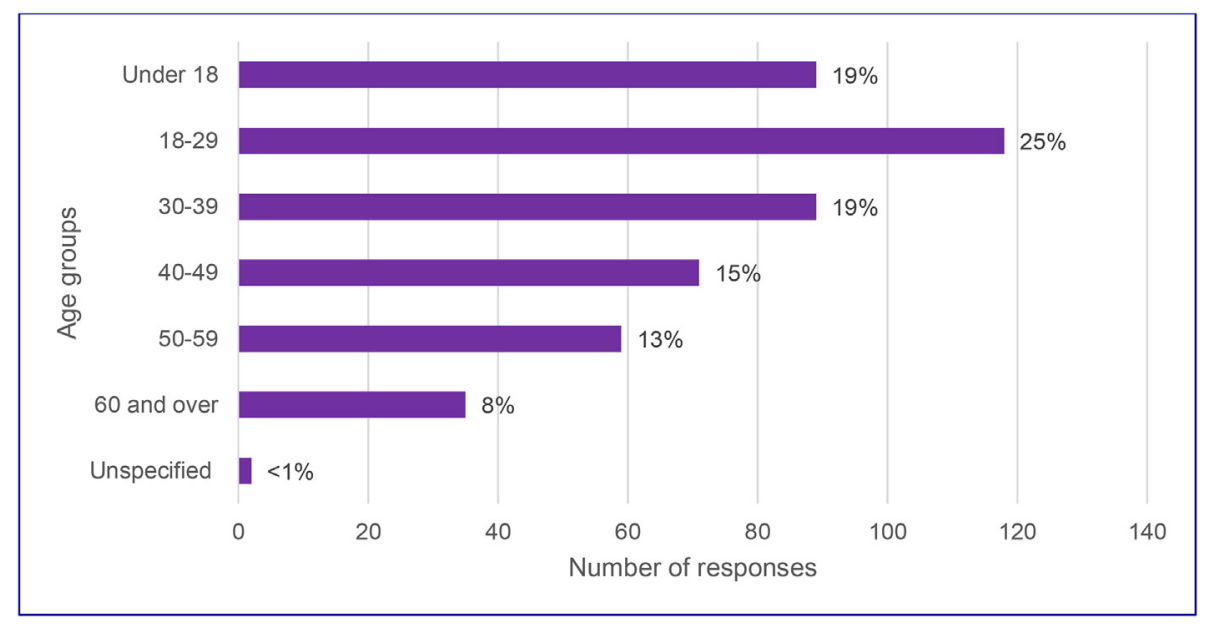

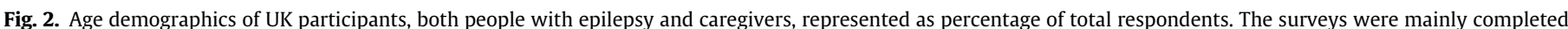

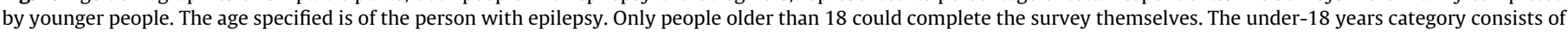
caregivers completing the caregiver surveys for children with epilepsy. 


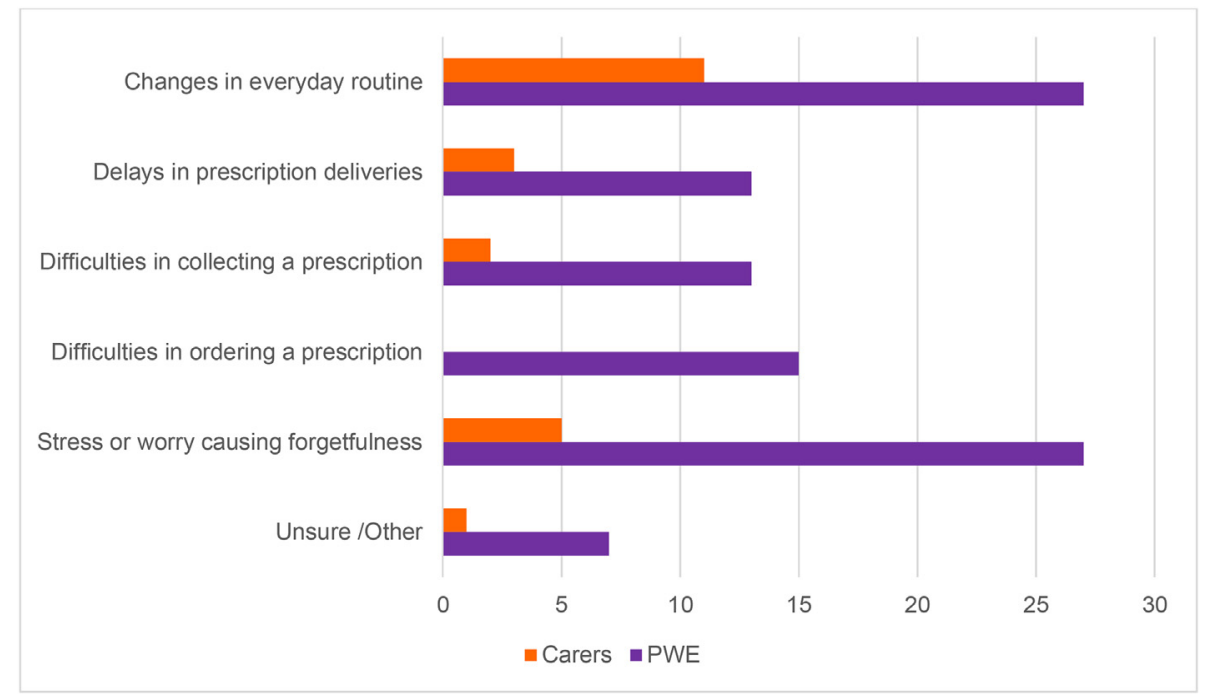

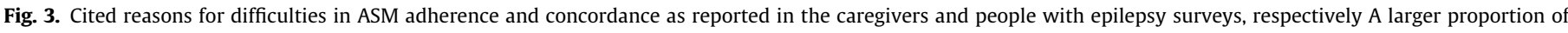

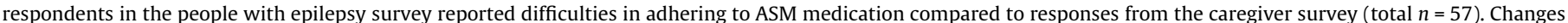
in everyday routine was cited as the most common cause of nonadherence in both surveys, followed by stress or worry resulting in forgetfulness.

Table 2

Reported causes of negative changes in respondent's health and wellbeing, extracted from qualitative survey data. Coding of qualitative data provides additional insights into respondent's perception of their own health and wellbeing. These illustrate external factors related to the first wave of COVID-19 that are reported to have resulted in adverse health outcomes.

\begin{tabular}{ll}
\hline Perceived causes for changes in health & Number of responses \\
\hline Difficulties in acquiring prescriptions & 1 \\
Difficulty in receiving healthcare & 7 \\
Adjusting medication during lockdown & 1 \\
Stress and anxiety related to COVID-19 & 7 \\
Changes to weight or fitness & 3 \\
Job instability & 1 \\
\hline
\end{tabular}

\subsubsection{People with epilepsy aged over 60 years}

People over the age of 60 years reported the highest prevalence of diabetes, heart conditions, hypertension, and memory difficul- ties. Frequency of mental health difficulties and respiratory conditions was lower than the overall average (Table 4). Fewer individuals in this older cohort reported changes to their overall health and well being during the COVID-19 pandemic compared with the wider dataset. A smaller proportion reported difficulty in taking ASMs on time and accessing epilepsy care (Table 4). There were, however, multiple other areas in which the risks to older people with epilepsy could be modified. In this demographic, for example, $35 \%$ of individuals accessed a health specialist less than once a year $(n=12), 35 \%$ lived alone $(n=12)$, and $26 \%$ were living with someone who would not be able to provide first aid $(n=9)$.

\subsubsection{Clinically vulnerable to COVID-19}

When limiting analysis to individuals who have diabetes, hypertension, heart conditions, or respiratory conditions (total $n=97$ ), a higher proportion of respondents reported epilepsyrelated changes to their health $(56 \%, n=48 / 97)$. Overall, $23 \%$

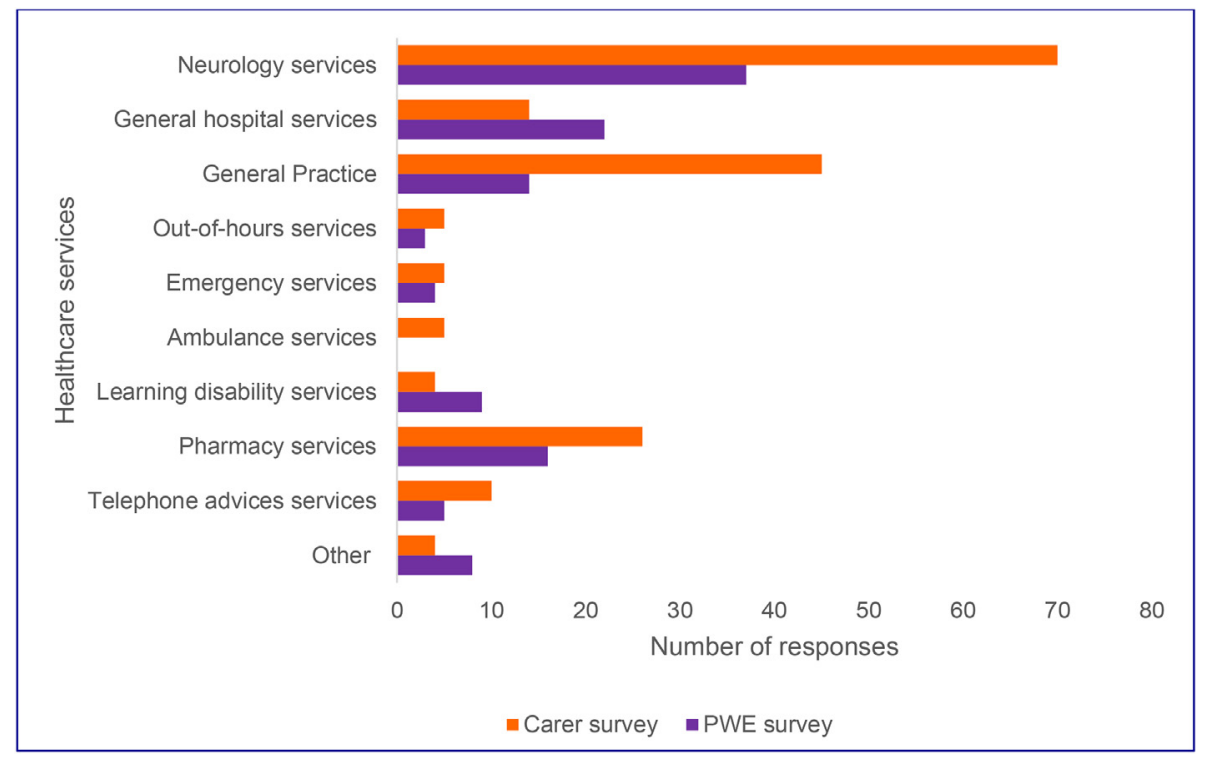

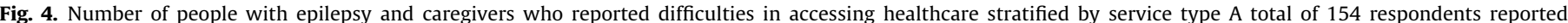

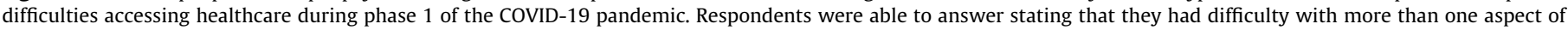
health care and so raw numbers of respondents are presented. 


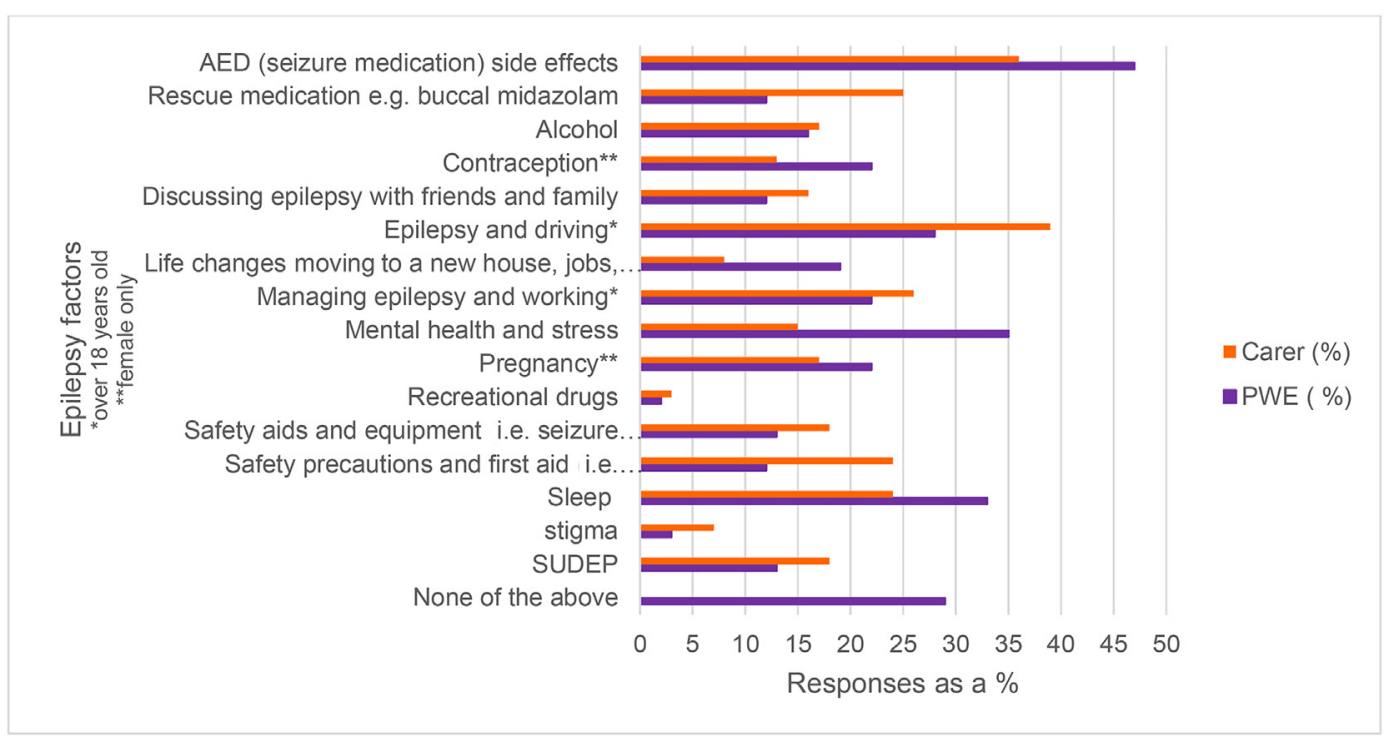

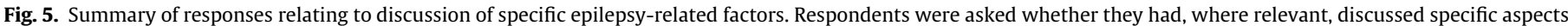

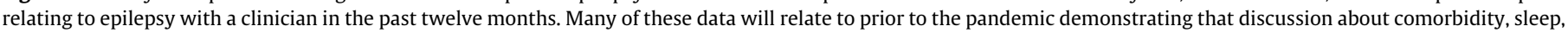

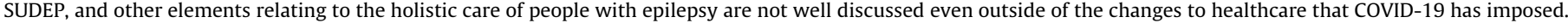

Table 3

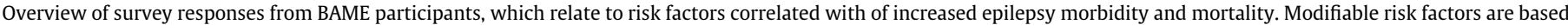

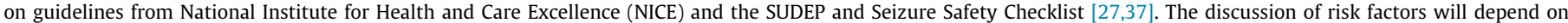

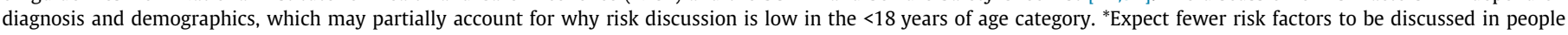
under 18 years of age (i.e. driving, employment) ${ }^{* *}$ Excluding pregnancy and contraception risk factors in male participants.

\begin{tabular}{|c|c|c|c|c|c|c|c|c|c|}
\hline \multirow{4}{*}{$\begin{array}{l}\text { Respondents by } \\
\text { ethnicity }\end{array}$} & \multirow{4}{*}{ Gender } & \multirow{4}{*}{ Age } & \multicolumn{7}{|l|}{$\underline{\text { Risk Factors }}$} \\
\hline & & & \multirow{3}{*}{$\begin{array}{l}\text { Epilepsy } \\
\text { consultations } \\
\text { a year } \\
<1=\text { increased } \\
\text { risk }\end{array}$} & \multirow{3}{*}{$\begin{array}{l}\text { Injuries (in } \\
12 \text { months) } \\
\text { Yes = increased } \\
\text { risk }\end{array}$} & \multirow{3}{*}{$\begin{array}{l}\text { Forgetfulness } \\
\text { taking ASMs } \\
\text { Yes/sometimes = } \\
\text { increased risk }\end{array}$} & \multicolumn{3}{|c|}{ During COVID-19 } & \multirow{3}{*}{$\begin{array}{l}\text { Discussion of risk } \\
\text { factors (in } \\
12 \text { months) } \\
\text { Fewer risk factors } \\
\text { discussed = } \\
\text { increase risk }\end{array}$} \\
\hline & & & & & & $\begin{array}{l}\text { Difficulty } \\
\text { taking } \\
\text { ASMs }\end{array}$ & $\begin{array}{l}\text { Changes } \\
\text { to health }\end{array}$ & $\begin{array}{l}\text { Difficulty } \\
\text { accessing } \\
\text { epilepsy } \\
\text { services }\end{array}$ & \\
\hline & & & & & & \multicolumn{3}{|c|}{ Yes $=$ increased risk } & \\
\hline \multirow[t]{3}{*}{ Asian/Asian British $(n=3)$} & Female & $50-59$ & 2 & No & No & No & No & No & $4 / 16$ \\
\hline & Male & $<18$ & $6+$ & No & No & No & No & Yes & $2 / 16^{*}$ \\
\hline & Female & $40-49$ & $6+$ & Yes & No & No & No & No & $3 / 16$ \\
\hline \multirow{2}{*}{$\begin{array}{l}\text { Black/African/Caribbean/ } \\
\text { Black British }(n=2)\end{array}$} & Female & $18-29$ & $<1$ & No & Sometimes & No & Yes & Yes & $5 / 16$ \\
\hline & Male & $30-39$ & 1 & Yes & No & No & No & No & $4 / 14^{* *}$ \\
\hline \multirow[t]{3}{*}{ Latinx/British Latinx $(n=3)$} & Female & $30-39$ & 2 & Yes & Sometimes & Yes & Yes & Yes & $5 / 16$ \\
\hline & Female & $<18$ & 4 & Yes & No data & Yes & Yes & Yes & $0 / 16^{*}$ \\
\hline & Male & $40-49$ & 1 & No & Sometimes & No & Unsure & No & $0 / 14^{* *}$ \\
\hline
\end{tabular}

noticed an increase in seizures $(n=22 / 97)$, 34\% experienced disrupted sleep ( $n=33 / 97)$, and $43 \%$ reported increased mental strain ( $n=42 / 97)$. Thirty-seven percent reported difficulty in accessing epilepsy services $(n=36 / 97)$.

\subsubsection{Pregnancy}

Five respondents, all aged between 30 and 39 years, reported being pregnant. All were living with other household members who could provide first aid. While the sample size is small, this cohort is possibly reflective of the broader data regarding health changes and accessing epilepsy services (Table 5). This group showed low engagement in epilepsy services and poorer risk communication [27], despite being a high-risk group for COVID-19 and epilepsy-related mortality.

\section{Discussion}

The COVID-19 pandemic is having an unparalleled global impact with far-reaching consequences on health and social care.
While significant emphasis has been placed on the direct health impacts of COVID-19, our results suggest that people with epilepsy have also experienced a decline in health and well-being. Survey respondents reported increased seizure frequency and seizure intensity, decreased adherence to ASMs, impaired mental health, and, in some instances, increased substance or alcohol use. These factors can lead to increased seizure activity in people with epilepsy and heighten the potential for premature death from SUDEP, unintentional injuries, or suicide $[11,27,28]$ Crucially, these changes have occurred in the context of restricted healthcare provision, reducing capacity to address concerns [39]. The vulnerability appears to be compounded by the deficiency in risk awareness and insufficient engagement with healthcare services before and during the pandemic.

Rates of seizure-related deaths and SUDEP correlate with increased seizure frequency and insufficient engagement with clinicians [20-23,28,40-41]. Without appropriate medical attention, indicators that point to an increased likelihood of premature mortality may not be identified, restricting the ability to intervene [28]. 
Table 4

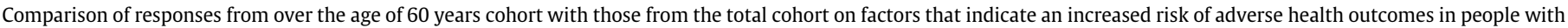

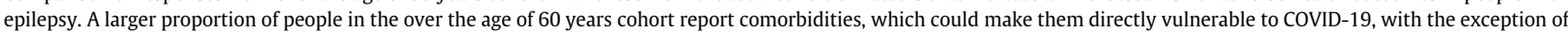

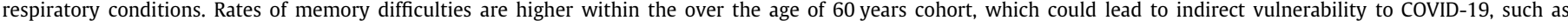

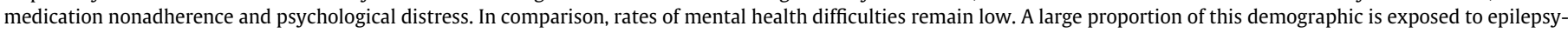
specific risk factors that correlate with increased risk of morbidity and premature mortality $[27,40]$.

\begin{tabular}{|c|c|c|c|}
\hline & & Rates in over the age of 60 years cohort & Rate in total cohort \\
\hline \multirow[t]{4}{*}{ Comorbidities (Directly vulnerable to COVID-19) } & Diabetes & $3 \%(n=1)$ & $2 \%(n=7)$ \\
\hline & Heart conditions & $12 \%(n=4)$ & $5 \%(n=23)$ \\
\hline & Hypertension & $26 \%(n=9)$ & $5 \%(n=23)$ \\
\hline & Respiratory conditions & $9 \%(n=3)$ & $10 \%(n=44)$ \\
\hline \multirow[t]{2}{*}{ Comorbidities (Indirectly vulnerable to COVID-19) } & Mental health & $6 \%(n=2)$ & $27 \%(n=123)$ \\
\hline & Memory difficulties & $47 \%(n=16)$ & $31 \%(n=143)$ \\
\hline \multirow[t]{3}{*}{ Epilepsy-related risk indicators for adverse health outcomes } & Changes to health & $26 \%(n=9)$ & $40 \%(n=185)$ \\
\hline & Difficulty in taking medication on time & $3 \%(n=1)$ & $13 \%(n=57)$ \\
\hline & Difficulty accessing epilepsy care & $18 \%(n=6)$ & $33 \%(n=154)$ \\
\hline
\end{tabular}

Table 5

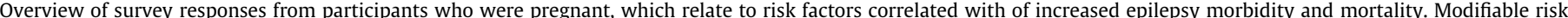

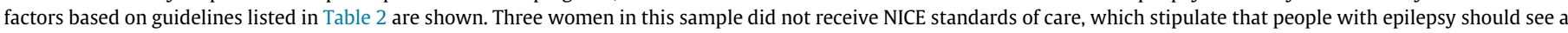

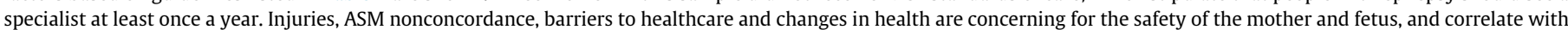
high levels of maternal mortality in people with epilepsy [38]. ASM = anti-seizure medication.

\begin{tabular}{|c|c|c|c|c|c|c|c|c|}
\hline \multirow{4}{*}{ ID } & \multirow{4}{*}{$\begin{array}{l}\text { Comorbid } \\
\text { conditions }\end{array}$} & \multicolumn{7}{|l|}{ Risk Factors } \\
\hline & & \multirow{3}{*}{$\begin{array}{l}\text { Epilepsy } \\
\text { consultations in a } \\
\text { year } \\
<1=\text { increased risk }\end{array}$} & \multirow{3}{*}{$\begin{array}{l}\text { Injuries (in } \\
12 \text { months) } \\
\text { Yes }=\text { increased } \\
\text { risk }\end{array}$} & \multirow{3}{*}{$\begin{array}{l}\text { Forgetfulness taking } \\
\text { ASMs } \\
\text { Yes/sometimes = increased } \\
\text { risk }\end{array}$} & \multicolumn{3}{|c|}{ During COVID-19 } & \multirow{3}{*}{$\begin{array}{l}\text { Discussion of risk factors } \\
\text { (past } 12 \text { months) } \\
\text { Fewer risk factors } \\
\text { discussed = increased risk }\end{array}$} \\
\hline & & & & & $\begin{array}{l}\text { Difficulty } \\
\text { taking ASMs }\end{array}$ & $\begin{array}{l}\text { Changes } \\
\text { to health }\end{array}$ & $\begin{array}{l}\text { Difficulty accessing } \\
\text { epilepsy services }\end{array}$ & \\
\hline & & & & & \multicolumn{3}{|c|}{ Yes $=$ increased risk } & \\
\hline 1 & None & $<1$ & No & Sometimes & Yes & Yes & $\mathrm{No}^{*}$ & $0 / 16$ \\
\hline 2 & None & $<1$ & No & Never & No & Yes & Yes & $3 / 16$ \\
\hline 3 & Dyspraxia & $<1$ & No & Sometimes & Yes & No & No & $2 / 16$ \\
\hline 4 & $\begin{array}{l}\text { Memory } \\
\text { difficulties }\end{array}$ & 3 & Yes & Sometimes & No & No & No & $7 / 16$ \\
\hline 5 & None & 1 & No & Never & No & No & No & $2 / 16$ \\
\hline
\end{tabular}

The risk of mortality may increase owing to poor communication about risk. This can disempower people and inhibit their ability to make informed decisions on, for example, ASM adherence, alcohol and nonprescription drug consumption, family planning, driving, and sleep habits [28].

Epilepsy-associated risk, including premature mortality, is greater in lower socioeconomic groups, who make up the largest proportion of epilepsy cases in the UK [42]. These groups are already predisposed to higher levels of comorbidities and experience more years of life lost to disability [11,43-44]. This can hinder an individual's stability and financial resilience, contributing to a decrease in earning potential and employment opportunities when unwell [11,42-45]. As services reconstitute, clinicians must engage in comprehensive communication to ascertain the specific needs of individuals, alongside an appraisal of their physical health, psychosocial well-being, and the interrelation between these components. To achieve this, a multimodal approach that includes social and economic interventions is essential.

Enabling good communication and accessibility are crucial in optimizing health care for people with chronic illness. Our study suggests that increased usage of remote consultations during the pandemic will benefit some, but may be a barrier for others (section 3.2.2.4). Ascertaining individual needs may streamline service provision, ensuring that those who benefit from face-to-face consultations can be prioritized in line with current capacities. Greater consensus on the role of technologies in medical care may facilitate better communication between healthcare providers. This could help avoid delays in referrals, treatments, or changes to medication regimes as well as alleviating confusion and uncertainty for people regarding their entitlements to healthcare.
To ensure that any potential gaps in care are mitigated, bestpractice resources, such as the SUDEP \& Seizure Safety Checklist, can be useful. These are able to provide personalized advice on reducing risks, including those that are of increasing relevance during the current circumstances [47]. Self-monitoring between appointments may also be beneficial for individuals in tracking their own experiences and behaviors, particularly when healthcare delivery is less straightforward. Resources such as EpSMon epilepsy self-monitoring app $[28,46]$ and other technologies may empower individuals day-to-day and support them in monitoring and reflecting on their health while simultaneously providing resources to educate on risk reduction strategies [47-50].

Efforts should be made to ensure equitable health interventions that recognize the increased needs of special groups, a facet which has been highlighted previously in work examining the effect of COVID and lockdowns on children with epileptic encephalopathies [51,52]. COVID-19 disproportionately affects people of BAME heritage and the elderly [15-16,34-35], while the incidence of epilepsy is highest in older people and those from lower socioeconomic groups [17-18,42]. Despite extensive social media messaging, we only received small numbers of respondents from BAME and older communities. Indirectly, this highlights the need for a tailored approach to allow information to reach people from these groups [53-55]. Clinicians must be vigilant to the specific needs of increasingly diverse populations.

\section{Limitations}

Our study has limitations, predominantly relating to the need for the surveys to be online and owing to data anonymization. 
Participant self-selection could introduce bias, meaning our findings cannot be extrapolated to the entire population with epilepsy. Variable reporting was partially identified through analysis, but some inconsistencies in reporting may remain. We cannot quantify health changes due to the absence of baseline data before the pandemic and the possibility of recall bias [56]. Also certain questions will need refining in future iterations as, for example, people could report a change in their seizures without necessarily specifying in which direction (worsening or improvement) that change was. Qualitative data enable us to conclude that some individuals have noticed deterioration in seizure control. With the second version of the surveys, more quantitative data on this aspect will be sought.

Socioeconomically vulnerable groups are under-represented (including those who are homeless, the elderly, ethnic minorities, LGBTQ+, and those with additional disabilities). These disparities can be partly attributed to the dependence on utilizing a text survey on an online platform which may not be accessible for all prospective participants [57]. Those marginalized by health and social care providers may be more reluctant to engage in research $[53,54]$. We aim to overcome these barriers as the study progresses by providing the surveys in multiple languages and increasing our efforts in engaging with outreach groups. Anonymous data collection using digital means may also facilitate greater inclusion of those who feel socially stigmatized and are more active in online spaces $[55,58]$.

\section{Conclusion}

COVID-19 has caused a paradigm shift in healthcare provision. As the UK currently witnesses its second wave of cases, it is essential that those involved in healthcare delivery can ensure optimal care for people with epilepsy. A multifaceted, person-centered approach with appropriate use of currently available technologies can help bridge the emerging gap in healthcare provision, while mitigating the rising risks associated with epilepsy-related mortality. These interventions must also account for varying needs and levels of risk within populations. The results of the COV-E study carry relevance that extends beyond epilepsy care, and highlight themes that apply to many other long-term chronic illnesses $[1,2,36]$. Moving forward, we hope our research will facilitate further awareness and tailored targeting of strategies to help improve the care of people with epilepsy during and after the pandemic. We also hope to inspire a broader body of research on COVID-19 and its impact on people with chronic illnesses.

\section{Declaration of Competing Interest}

The authors declare that they have no known competing financial interests or personal relationships that could have appeared to influence the work reported in this paper.

\section{Acknowledgements}

This study was funded by SUDEP Action Registered charity 1164250 (England \& Wales) and supported by the Oxford NIHR Biomedical Research Centre.

Conflicts of interest: The authors declare no direct conflicts of interest in relation to this work.

We are grateful to all of the following organizations, and many individuals whom we are unable to name individually, for promoting this work through online platforms. We also very much appreciate the valuable input of all the respondents who have completed the surveys.

BAND Foundation.

Dravet Syndrome UK.
Epilepsy Action.

Epilepsy Connections.

Epilepsy Foundation America.

Epilepsy Research UK.

Epilepsy Society.

Epilepsy Sparks.

IBE.

ILAE - British Branch.

Matthew's Friend.

Neurological Alliance.

SUDEP Action.

PP is supported by the National Health and Medical Research Council (APP1163708), the Epilepsy Foundation, the Royal Australasian College of Physicians, Melbourne Health, and Monash University. DMA is supported by EpLink, Dravet Syndrome Foundation, McLaughlin grants. NJ is the Bludhorn Professor of International Medicine and receives grant funding from NINDS (NIH U24NS107201, NIH IU54NS100064) and PCORI. JHC is supported by the National Institute of Health Research (NIHR) Biomedical Research Centre at Great Ormond Street Hospital, NIHR, Engineering and Physical Sciences Research Council, GOSH Charity, Epilepsy Research UK, and the Waterloo Foundation. JWS is based at UCLH/ UCL Comprehensive Biomedical Research Centre, which receives a proportion of funding from the UK Department of Health's NIHR Biomedical Research Centres funding scheme. He receives support from the Dr Marvin Weil Epilepsy Research Fund, the Christelijke Vereniging voor de verpleging van Lijders aan Epilepsie, The Netherlands, and the UK Epilepsy Society. AS is supported by the Oxford NIHR Biomedical Research Centre at the John Radcliffe Hospital, UK.

\section{Appendix A. Supplementary data}

Supplementary data to this article can be found online at https://doi.org/10.1016/j.yebeh.2020.107658.

\section{References}

[1] World Health Organization. COVID-19 significantly impacts health services for noncommunicable diseases. WHO. 2020. Available online: https://www.who. int/news-room/detail/01-06-2020-covid-19-significantly-impacts-healthservices-for-noncommunicable-diseases [Date accessed: 7 October 2020].

[2] World Health Organization. Maintaining essential health services: operational guidance for the COVID-19 context: interim guidance. Geneva: WHO; 2020. p. $1-61$.

[3] NHS England. COVID-19 Daily Deaths. 2020. Available online: https://www. england.nhs.uk/statistics/statistical-work-areas/covid-19-daily-deaths/ [Date accessed: 7 October 2020].

[4] French AJ, Brodie MJ, Caraballo R, Devinsky O, Ding D, Jehi L, et al. Keeping people with epilepsy safe during the COVID-19 pandemic. Neurology 2020;94 (23):1032-7. https://doi.org/10.1212/WNL.0000000000009632.

[5] Kuroda N. Epilepsy and COVID-19: associations and important considerations. Epilepsy Behav 2020;108:107122.

[6] Fonseca E, Quintana M, Lallana S, Restrepo JL, Abraira L, Santamarina E, et al. Epilepsy in time of COVID-19: a survey based study. Acta Neurol Scand 2020. https://doi.org/10.1111/ane.13335.

[7] Huang S, Wu C, Jia Y, Li G, Zhu Z, Lu K, et al. COVID-19 outbreak: the impact of stress on seizures in patients with epilepsy. Epilepsia 2020. https://doi.org/ 10.1111/epi.16635. 10.1111/epi.16635.

[8] Tian N, Boring M, Kobau R, Zack MM, Croft JB. Active epilepsy and seizure control in Adults - United States, 2013 and 2015. Morbidity and Mortality Weekly Report (MMWR). Available online: https://www.cdc.gov/mmwr/ volumes/67/wr/mm6715a1.htm?s_cid=mm6715a1_w [accessed 7 October 2020].

[9] Hovinga CA, Asato MR, Manjunath R, Wheless JW, Phelps SJ, Sheth RD, et al. Association of non-adherence to antiepileptic drugs and seizures, quality of life, and productivity: survey of patients with epilepsy and physicians. Epilepsy Behav 2002;13(2):316-22. https://doi.org/10.1016/j.yebeh.2008.03.009.

[10] O'Rourke G, O'Brien JO. Identifying the barriers to antitepileptic drug adherence among adults with epilepsy. Seizure 2017;45:160-8. https://doi. org/10.1016/i.seizure.2016.12.006.

[11] World Health Organization. Epilepsy: a public health imperative. Geneva: WHO; 2019. p. 1-144. 
[12] Mummery CJ, Kipps MC. UK neurology response to the COVID-19 crisis. Clin Med (Lond) 2020;20(3):266-9.

[13] British Medical Association. COVID-19: video consultations and homeworking. Available online: https://www.bma.org.uk/advice-and-support/covid-19/ adapting-to-covid/covid-19-video-consultations-and-homeworking. [Date accessed: 7 October 2020].

[14] Association of British Neurologists. ABN COVID-19 guidance and advice. Available online: https://www.theabn.org/page/covid19_response. [Date accessed: 7 October 2020].

[15] Public Health England. Disparities in the risk and outcomes of COVID-19. 2020. 4-76 Available online: https://assets.publishing.service.gov.uk/government/ uploads/system/uploads/attachment_data/file/908434/ Disparities_in_the_risk_and_outcomes_of_COVID_August_2020_update.pdf [Date accessed: 7 October 2020].

[16] Public Health England. Beyond the data: Understanding the impact of COVID19 on BAME groups. 2020. 1-69 Available online: https://assets.publishing. service.gov.uk/government/uploads/system/uploads/attachment_data/file/ 892376/COVID_stakeholder_engagement_synthesis_beyond_the_data.pdf [Date accessed: 7 October 2020].

[17] Burneo J, Jette N, Theodore W, et al. Disparities in epilepsy: report of a systematic review by the North American Commission of the International League Against Epilepsy. Epilepsia 2009;50(10):2285-95.

[18] Schiltz N, Koroukian S, Mendel E, et al. Disparities in access to specialized epilepsy care. Epilepsy Res 2013;107. 10.1016.

[19] Shallcross A, Becker D, Singh A, et al. Psychosocial factors associated with medication adherence in ethnically and socioeconomically diverse patients with epilepsy. Epilepsy Behav 2015;46:242-5.

[20] Morrish P, Duncan S, Cock H. Epilepsy deaths: learning from health service delivery and trying to reduce risk. Epilepsy Behav 2019;103:. https://doi.org/ 10.1016/j.yebeh.2019.106473106473.

[21] Pickrell WO, Kerr MP. SUDEP and mortality in epilepsy: The role of routinely collected healthcare data, registries, and health inequalities. Epilepsy Behav 2019;103. https://doi.org/10.1016/i.yebeh.2019.106453.

[22] Mbizvo GK, Bennett K, Simpson CR, Duncan SE, Chin RFM. Epilepsy-related and other causes of mortality in people with epilepsy: a systematic review of systematic reviews. Epilepsy Res 2019;157:106192.

[23] Ridsdale L, Charlton J, Ashworth M, Richardson MP, Gulliford MC. Epilepsy mortality and risk factors for death in epilepsy: a population-based study. Br J Gen Pract 2011;61(586):e271-8.

[24] Public Health England. Government dashboard on Coronavirus (COVID-19) in the UK. 2020 Available online: https://coronavirus.data.gov.uk [Date accessed: 7 October 2020].

[25] Allen H, Katz R. Demography and public health emergency preparedness: Making the connection. Popul Res Policy Rev 2020;29(4):527-39.

[26] Cabinet Office. Ethnicity facts and figures: List of ethnic groups. Available online: https://www.ethnicity-facts-figures.service.gov.uk/style-guide/ethnicgroups [Date accessed: 8 October 2020].

[27] Shankar R, Ashby S, McLean B, Newman C. Bridging the gap of risk communication and management using the SUDEP and Seizure Safety Checklist. Epilepsy Behav 2019;103:106419.

[28] Sveinsson O, Andersson T, Mattsson P, Carlsson S, Tomson T. Clinical risk factors in SUDEP: a nationwide population-based case-controlled study. Neurology 2020;94(4):e419-29.

[29] Green J, Thorogood N. Qualitative methods for health research. 3rd ed. London: Sage Publications Ltd; 2014. p. 209-22.

[30] Schoonenboom J, Johnson RB. How to construct a mixed methods research design. Kolner Z Soz Sozphyschol. 2017;69(2):107-31.

[31] Etz KE, Arroyo JA. Small sample research: considerations beyond statistical power. Prev Sci 2015;16:1033-6.

[32] Office for National Statistics. Ethnic group, national identity and religion: A guide for the collection and classification of ethnic group, national identity and religion data in the UK. 2016. Available online: https://www.ons.gov.uk/ methodology/classificationsandstandards/measuringequality/ ethnicgroupnationalidentityandreligion [Date accessed 8 October 2020].

[33] Burton J, Nandi A, Platt L. Who are the UK's minority ethnic groups? Issues of identification and measurement in a longitudinal study. Institute of Social and Economic Research. Working Paper, 2008. Available online: https://www.iser. essex.ac.uk/files/iser_working_papers/2008-26.pdf. [Date accessed: 8 October 2020].

[34] Atkins JL, Masoli JAH, Delgado J, Pilling L, Kuo CL, Kuchel GA, et al. Preexisting comorbidities predicting COVID-19 mortality in the UK Biobank community cohort. J Gerontol Series A 2020;glaa183. https://doi.org/10.1093/gerona/ glaa183.

[35] NHS. Who's at higher risk from coronavirus. 2020. Available online: https:// www.nhs.uk/conditions/coronavirus-covid-19/people-at-higher-risk/whosat-higher-risk-from-coronavirus/ [Date accessed: 8 October 2020].
[36] Office for National Statistics. Direct and indirect impacts of COVID-19 on excess deaths and morbidity: executive summary. 2020. Available online: https://assets.publishing.service.gov.uk/government/uploads/system/ uploads/attachment_data/file/907616/s0650-direct-indirect-impacts-covid19-excess-deaths-morbidity-sage-48.pdf [Date accessed: 8 October 2020].

[37] NICE. Epilepsies: diagnosis and management. 2020. Available at: https://www. nice.org.uk/guidance/cg137/chapter/1-Guidance [Date accessed: 8 October 2020].

[38] Knight M, Nair M, Tuffnell D, Shakespeare J, Kenyon S, Kurinczuk JJ (Eds.) on behalf of MBRRACE-UK. Saving Lives, Improving Mothers' Care - Lessons learned to inform maternity care from the UK and Ireland Confidential Enquiries into Maternal Deaths and Morbidity 2013-15. Oxford: National Perinatal Epidemiology Unit, University of Oxford 2017.

[39] British Medical Association. Pressure points in the NHS. 2020. Available online: https://www.bma.org.uk/advice-and-support/nhs-delivery-and-workforce/ pressures/pressure-points-in-the-nhs [Date accessed: 8 October 2020].

[40] Shankar R, Jailhal V, Walker M, Pace A, Cox D, Brown S. A community study in Cornwall UK of sudden unexpected death in epilepsy (SUDEP) in a 9-year population sample. Seizure 2014;23(5):382-5.

[41] Shankar R, Newman C, Hanna J, Ashton J, Jory C, McLean B, et al. Keeping patients with epilepsy safe: a summountable challenge. BMJ Open Quality 2015;4(u208167):. $\quad$ https://doi.org/10.1136/bmiquality.u208167.w3252 w3252.

[42] Steer S, Pickrell WO, Kerr MP, Thomas RH. Epilepsy prevalence and socioeconomic deprivation in England. Epilepsia 2014:55(10):1634-41.

[43] World Health Organization. Epilepsy: Key facts. 2019. Available online: https://www.who.int/en/news-room/fact-sheets/detail/epilepsy [Date accessed: 8 October 2020].

[44] The Institute for Health Metrics and Evaluation. The Global Burden of Disease (GBD) project: GBD compare. Available online: https://vizhub.healthdata.org/ gbd-compare/ [Date accessed: 8 October 2020].

[45] Thorpe J, Viney K, Hensing G, Lönnroth K. Income security during periods of ill health: a scoping review of policies, practice and coverage in low-income and middle-income countries. BMJ Global Health 2020;5:e002425.

[46] McLean B, Shankar R, Hanna J, Jory C, Newman C. Sudden unexpected death in epilepsy: measures to reduce risk. Pract Neurol 2017;17:13-20.

[47] NHS Rightcare. Epilepsy toolkit optimizing a system for people living with epilepsy. 2020. Available online: https://www.england.nhs.uk/rightcare/wpcontent/uploads/sites/40/2020/03/rightcare-epilepsy-toolkit-v2.pdf [Date accessed 8 October 2020].

[48] World Health Organization. WHO Information Kit on Epilepsy: what you can do. Geneva: WHO; 2015. p. 3-42.

[49] NHS. Living with epilepsy. 2020. Available online: https://www.nhs. uk/conditions/epilepsy/living-with/ [Date accessed 20 October 2020].

[50] SUDEP Action: Information: Epilepsy and risk. Available online: https://sudep. org/epilepsy-and-risk [Date accessed: 8 October 2020].

[51] Aledo-Serrano A, Mingorance A, Jiménez-Huete A, Toledano R, García-Morales I, Anciones C, et al. Genetic epilepsies and COVID-19 pandemic: Lessons from the caregiver perspective. Epilepsia 2020;61(6):1312-4. https://doi.org/ 10.1111/epi.16537.

[52] Kumar Sahu J, Madaan P, Chand P, Amit Kumar A, Linn K, Lhamu Mynak M, et al. Management of West syndrome during COVID-19 pandemic: a viewpoint from South Asian West Syndrome Research Group. Epilepsy Res. 2020;167 (106453). https://doi.org/10.1016/j.eplepsyres.2020.106453.

[53] Owen-Smith AA, Woodyatt C, Sineath RC, Hunkeler EM, Barnwell TL, Graham A, et al. Perceptions of barriers to and facilitators of participation in health research among transgender people. Transgender Health 2016;1(1):187-96. https://doi.org/10.1089/trgh.2016.0023.

[54] Dawson S, Campbell SM, Giles SJ, Morris RL, Cheraghi-Sohi S. Black and minority ethnic group involvement in health and social care research: a systematic review. Health Expect 2017;21(1):3-20. https://doi.org/10.1111/ hex.12597.

[55] McInroy LB. Pitfalls, potentials, and ethics of online survey research: LGBTQ and other marginalised and hard-to-access youths. Social Work Res 2016;40 (2):83-94. https://doi.org/10.1093/swr/svw005.

[56] Athubaiti A. Information bias in health research: definition, pitfalls, and adjustment methods. J Multidiscip Healthc 2016;9:211-7.

[57] Helsper EJ. Digital inclusion: an analysis of social disadvantage and the information society. 2013. Department for Communities and Local Government, London, UK. ISBN 9781409806141.

[58] Murdoch M, Simon AB, Polusny MA, Bangerter AK, Grill JP, Noorbaloochi S, et al. Impact of different privacy conditions and incentives on survey response rate, participant representativeness and disclosure of sensitive information: a randomized controlled trial. BMC Med Res Method 2014;14(90):2-11. https:/l doi.org/10.1186/1471-2288-14-90. 